\title{
Reduction of Palladium Ion by Sodium Ascorbate in Alkaline Electrolyzed Water
}

\author{
Toshikazu TAKENOUCHI*, Jun YOSHIIKE* and Shin-ichi WAKABAYASHI*
}

\author{
*SHINKO ELECTRIC INDUSTRY CO., LTD. (36, Kitaowaribe, Nagano-shi, Nagano 381-0014)
}

\begin{abstract}
The reaction to deposit the palladium nuclei by reducing the palladium complex adsorbing on the surface of the polyimide resin was examined using alkaline electrolyzed water containing sodium sulfate to which sodium ascorbate was added. As a result, the palladium nuclei could not form when they were used separately. But it has been confirmed that palladium nuclei formed when both of them coexisted. This palladium nuclei could be used as catalytic sites for the electroless nickel plating. The adhesive strength of the plated nickel layer was equivalent to that produced by a commercially available activator.
\end{abstract}

Keywords : Alkaline Electrolyzed Water, Palladium, Reduction, Sodium Ascorbate

\section{Introduction}

It is known that alkaline electrolyzed water has a large negative redox potential and reducing power ${ }^{1,2)}$. However, it is likely that alkaline electrolyzed water does not have the capability to produce metals by reducing metal oxides or metal ions, thus far metal deposition of metal oxide or metal ions using alkaline electrolyzed water has not yet been developed. Ascorbic acid is used as an antioxidant, however, in many cases, it cannot reduce metal ions by itself, but it is reported that it is used for electroless gold plating together with a reducing agent such as sodium sulfite $^{3)}$. The authors considered that the reducing capability might be improved and the reductive deposition of a metal might occur by combining the alkaline electrolyzed water and sodium ascorbate. From the background, the reductive deposition of the palladium ion adsorbed on the polyimide resin was examined using the alkaline electrolyzed water in which sodium ascorbate was added. As a result, it has been confirmed that palladium nuclei formed and performed as catalytic sites for the electroless nickel plating, and that a plating film with a sufficient adhesive strength was obtained.

\section{Experimental}

Table 1 lists the four kinds of aqueous solutions used in this experiment. No. 1:Alkaline electrolyzed water

Table 1 Solutions used in the experimental

\begin{tabular}{ll}
\hline No. 1 & $\begin{array}{l}\text { Alkaline electrolyzed water of } 0.1 \mathrm{M} \text { sodium sulfate solu- } \\
\text { tion }\end{array}$ \\
No. 2 & $\begin{array}{l}0.25 \mathrm{M} \text { sodium ascorbate solution } \\
\text { No. } 3\end{array}$ \\
& $\begin{array}{l}0.25 \mathrm{M} \text { of sodium ascorbate which was prepared by ad- } \\
\text { ding sodium ascorbate to alkaline electrolyzed water of } 0 .\end{array}$ \\
& $\begin{array}{l}1 \mathrm{M} \text { sodium sulfate } \\
\text { Nommercial reductant }\end{array}$ \\
& $\begin{array}{l}\text { Com } \\
\text { boric acid })\end{array}$
\end{tabular}

containing $0.1 \mathrm{M}$ sodium sulfate. No. 2:0.25 M sodium ascorbate aqueous solution. No.3:The alkaline electrolyzed water containing $0.1 \mathrm{M}$ sodium sulfate to which sodium asscorbate was added to make $0.25 \mathrm{M}$ sodium asscorbate solution. No. 4:A commercially available activator which contains dimethyl amine borane as the main component. A diaphragm-type electrolytic device (JED-007, MIZ Co., Ltd.) was used. $74 \mathrm{~mm} \times 113 \mathrm{~mm}$ titanium electrodes coated with a platinum film were used. The electrolysis was carried out at $0.72 \mathrm{~A} \mathrm{dm}^{-2}(0.6 \mathrm{~A}, 100 \mathrm{~V})$ for 15 minutes.

The procedure of reducing the palladium ion to the deposit was as follows. The polyimide resin (Kapton, Toray-DuPont Co., Ltd.) specimen was first activated by soaking in the sodium hydroxide type pre-processing solution (PFP conditioner, Okuno Chemical Industries Co., Ltd.) for 8 minutes at room temperature. The palladium complex was then adsorbed on the specimen by soaking in an aqueous solution containing the palladium complex (PFP catalyst of the same company) for 6 minutes at $40^{\circ} \mathrm{C}$. The palladium ion was reduced by soaking in each of the aqueous solutions indicated in Table 1 for 10 minutes at $80^{\circ} \mathrm{C}$. In order to confirm the formation of the metallic palladium layer, the electroless nickel plating was applied on the polyimide resin specimen to see any of nickel deposition happened, because the electroless nickel plating reaction does not occur unless a catalytic nucleus of metallic palladium forms. The electroless nickel plating was carried out at room temperature using the acid plating bath (PFP chemical nickel plating solution from the same company) containing nickel sulfate, sodium hypophosphite, and carboxylic acid. The surface of the polyimide resin specimen on which the metallic palladium had been deposited was observed by SEM (Scanning Electron Microscope:S-4500 I, Hitachi Ltd.), and analyzed by XPS (X-ray Photoelectron Spectroscope:AXIS-HS3. 5, Shimazu-Klatons). 
The electrochemical measurement system (HZ -3000, Hokuto Denko Co., Ltd.) was used for measuring the current-potential curves. A rotating electrode (platinum, $0.196 \mathrm{~cm}^{2}$ specific surface area, $1000 \mathrm{rpm}$ ) was used as the working electrode, a saturated calomel electrode for the reference electrode, and a platinum electrode for the counter electrode. The natural electrode potential was measured in the range from -0.8 to $0 \mathrm{~V}$ vs. SCE at a scan rate of $0.05 \mathrm{~V} / \mathrm{s}$. In addition, during the measurement, a $\mathrm{pH} 11.2$ buffer solution, which consisted of $0.35 \mathrm{M}$ disodium hydrogenphosphate and $0.05 \mathrm{M}$ sodium hydroxide, was added to each aqueous sample solution in order to suppress the change in the $\mathrm{pH}$ of the aqueous solution.
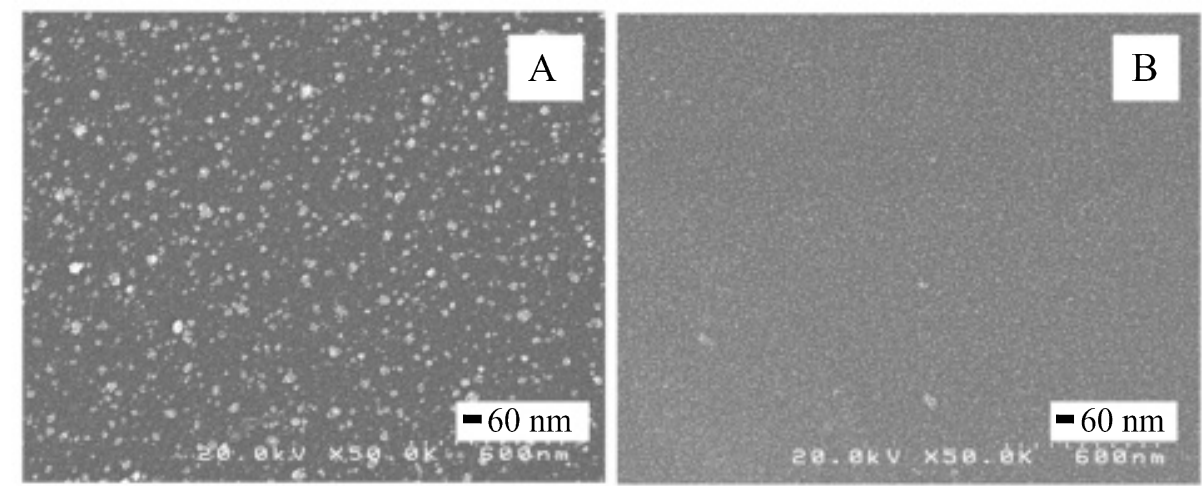

Fig. 1 SEM images of palladium deposited on polyimide resin

A:Reduced by the alkaline electrolyzed water with sodium ascorbate (No. 3),

B:Reduced by conventional reductant (No. 4).
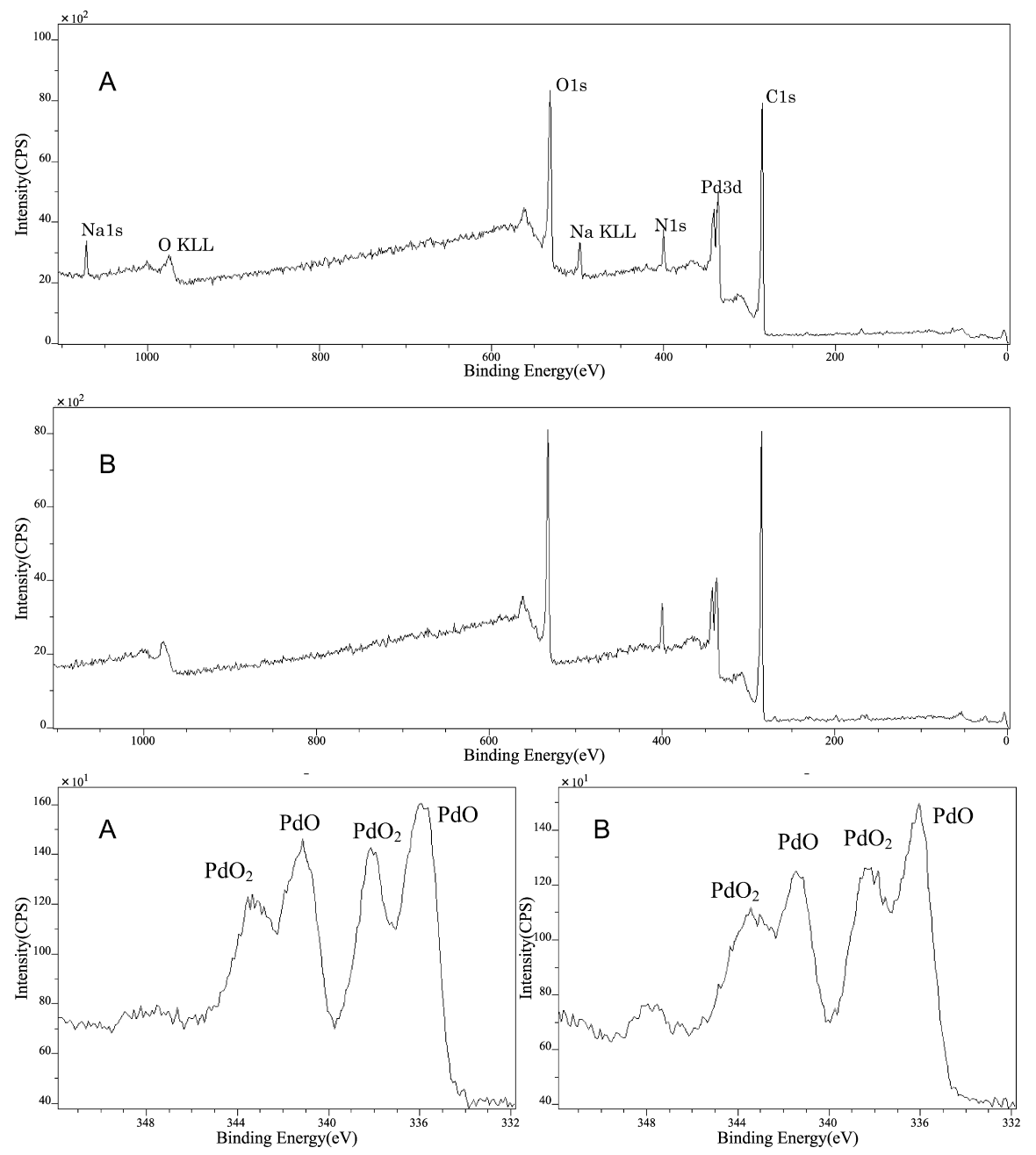

Fig. 2 Wide and narrow XPS spectra of palladium deposited on polyimide resin.

A:Reduced by the alkaline electrolyzed water with sodium ascorbate (No.3), B:Reduced by conventional reductant (No. 4). 


\section{Results and Discussion}

\section{1 Reduction of palladium ion}

When the specimen was processed with the No. 1 aqueous solution (alkaline electrolyzed water of sodium sulfate) or the No. 2 aqueous solution (sodium ascorbate aqueous solution), the formation of palladium nuclei were not observed on the polyimide surface by SEM. When the processing was done with the No. 3 aqueous solution (sodium ascorbate added to the alkaline electrolyzed water of sodium sulfate), the palladium nuclei were uniformly deposited on the polyimide surface, and their size was about $10 \mathrm{~nm}$. The palladium nuclei of several $\mathrm{nm}$ were deposited too, when using the No. 4 aqueous solution (commercially available activator, which contains dimethyl amine borane as the main component) for the processing. Figure 1 shows an SEM image of each deposited palladium. Figure 2 shows the results of the XPS analysis of each palladium nucleus. In the wide scanning range, the spectrum of the sample obtained from the No. 3 solution was almost the same as that from the No.4, except for the peaks corresponding sodium, which seemed to originate from sodium ascorbate. In the narrow scanning spectrum, the peaks of $\mathrm{PdO}$ and $\mathrm{PdO}_{2}$ were observed for the No. 3 and No. 4 solutions. It is likely that the palladium oxide peaks because the palladium surface was naturally oxidized to form the palladium oxides.

Moreover, the electroless nickel plating was applied to each sample. As a result, though nickel was not deposited on the specimen treated with the No. 1 and No. 2 solutions, a shiny plated layer was formed on the specimen treated with the No. 3 and No. 4 solutions. Furthermore, electrolytic copper plating was applied on these surfaces, and the peel strength was measured using the universal static mechanical testing machine (EZ Graph, Shimazu Ltd.). As a result, the strength was $1160 \mathrm{gf} / \mathrm{cm}$ for the No. 3 solution, and $1100 \mathrm{gf} / \mathrm{cm}$ for the No. 4 solution. The peeling off occurred at the interface between the polyimide resin and the electroless nickel plated layer, a strong bonding strength was obtained. Therefore, it was confirmed the palladium nuclei made a strong bond to electroless nickel layers.

\section{2 Current-potential curves}

Figure 3 shows the current-potential curves. On the platinum electrode, as for the No. 1 solution, the electrolytic current began to flow at $-0.8 \mathrm{~V}$ vs. SCE, and increased to $70 \mathrm{~mA} \mathrm{dm}{ }^{-2}$ at $-0.65 \mathrm{~V}$ vs. SCE. However, no increase in the current was observed even though the potential was further swept to the positive side. The alkaline electrolyzed water exhibited a small oxidation current value though it had a large negative redox potential. In the No. 2 solution, the oxidation current did not flow until $-0.32 \mathrm{~V}$ vs. SCE, and then rapidly increased to $550 \mathrm{~mA} \mathrm{dm}^{-2}$ at $0 \mathrm{~V}$ vs. SCE. It can be said that the sodium ascorbate aqueous solution has a weak reducing power because a certain oxidation current is not observed until the potential is scanned to high on the positive side. In the No. 3 solution, the oxidation current began to flow at $-0.8 \mathrm{~V}$ vs. SCE, and rapidly increased around $-0.30 \mathrm{~V}$ vs. SCE, and further increased to $1000 \mathrm{~mA}$ $\mathrm{dm}^{-2}$ at $-0.1 \mathrm{~V}$ vs. SCE. This current-potential curve is almost the combination between Curve No. 1 and Curve No.2. The oxidation current of No. 4 started to increase at $-0.52 \mathrm{~V}$, and it is understood that this solution has a strong reducing power. It can be said that the pH 11. 2 buffer solution, which consisted of $0.35 \mathrm{M}$ disodium hydrogenphosphate and $0.05 \mathrm{M}$ sodium hydroxide, was not involved in the electrode reaction because no anodic background current was observed. In addition, in the No. 1 solution, the potential where the oxidation current began to flow was more negative than that of the No. 4 solution, but the palladium ion could not be reduced. The reason cannot be explained at this moment. Moreover, though the anode reactions of No. 1 and 3 are not clarified at this moment, that of No. 2 is supposed to be formula 1 , that of No. 4 is shown in formula 2 or $3^{4)}$.

$$
\begin{aligned}
& \mathrm{C}_{6} \mathrm{H}_{7} \mathrm{~N}_{\mathrm{a}} \mathrm{O}_{6}+\mathrm{OH}^{-} \rightarrow \mathrm{C}_{6} \mathrm{H}_{6} \mathrm{NaO}_{6}+\mathrm{H}_{2} \mathrm{O}+\mathrm{e}^{-} \quad \cdots(1) \\
& \left(\mathrm{CH}_{3}\right)_{2} \mathrm{NHBH}_{3}+4 \mathrm{OH}^{-} \rightarrow \\
& \quad\left(\mathrm{CH}_{3}\right)_{2} \mathrm{NH}+\mathrm{BO}_{2}^{-}+3 / 2 \mathrm{H}_{2}+2 \mathrm{H}_{2} \mathrm{O}+3 \mathrm{e}^{-} \cdots(2) \\
& \left(\mathrm{CH}_{3}\right)_{2} \mathrm{NHBH}_{3}+7 \mathrm{OH}^{-} \rightarrow \\
& \quad\left(\mathrm{CH}_{3}\right)_{2} \mathrm{NH}+\mathrm{BO}_{2}^{-}+5 \mathrm{H}_{2} \mathrm{O}+6 \mathrm{e}^{-} \cdots \cdots \cdots \cdots \cdots(3)
\end{aligned}
$$

The stability of the No. 3 aqueous solution was examined. As a result, the oxidation current decreased with time, and three hour later became almost the same as that of the No. 2 curve. As for the No. 1 solution, the oxidation current also disappeared three hour later. Based on these results, the reducing power of the alkaline electrolyzed water is lost within

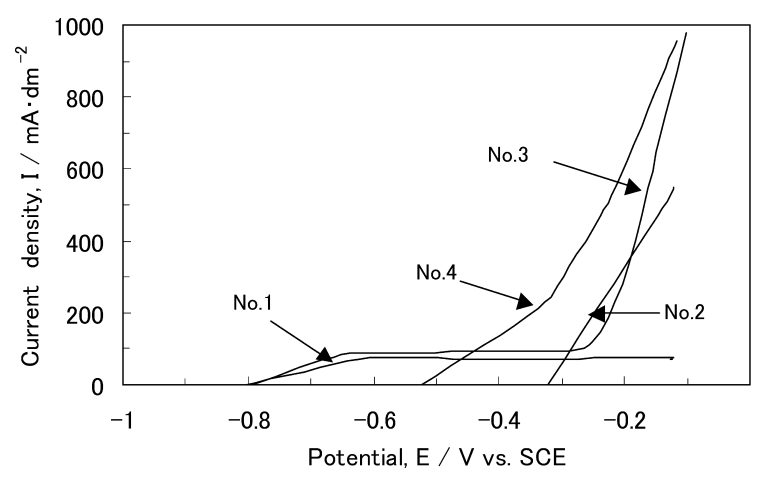

Fig. 3 I-E curve of each solutions.

No. 1:Alkaline electrolyzed water of $0.1 \mathrm{M}$ sodium sulfate solution, No. 2:0.25 M sodium ascorbate solution, No. 3:0.25 $\mathrm{M}$ of sodium ascorbate which was prepared by adding sodium ascorbate to alkaline electrolyzed water of $0.1 \mathrm{M}$ sodium sulfate, No. 4:Commercial reductant $(0.5 \%$ dimetylamineboron and $4 \%$ boric acid). Rotating electrode (platinum, $1000 \mathrm{rpm}$, surface area $0.196 \mathrm{~cm}^{2}$ ), saturated calomel electrode, and platinum electrode were used as working electrode, reference electrode, and counter electrode respectively. The measuring range was -0.8 to $0 \mathrm{~V}$ vs. SCE, swept forward at the scanning speed of $0.05 \mathrm{~V} / \mathrm{s}$. 
a short time. In the No. 1 and No. 3 aqueous solutions, the redox potential increased in a short time without being accompanied by a $\mathrm{pH}$ change. A large negative redox potential of the alkaline electrolyzed water may be attributed to dissolved hydrogen as suggested by the Nernst's equation. Therefore it is deduced that the disappearance of the dissolved hydrogen in the alkaline electrolyzed water lowers reducing power of the aqueous solution.

\section{Conclusions}

The reaction to deposit the palladium nuclei by reducing the palladium complex adsorbing on the surface of the polyimide resin was examined using alkaline electrolyzed water containing sodium sulfate to which sodium ascorbate was added. As a result, the palladium nuclei could not form when they were used separately. But it has been confirmed that palladium nuclei formed when both of them coexisted. This palladium nuclei could be used as catalytic sites for the electroless nickel plating. The adhesive strength of the plated nickel layer was equivalent to that produced by a commercially available activator. (Received January 19, 2006 ; Accepted February 20, 2006)

\section{References}

1) S. Shirahata, S. Kobayashi, M. Nakano, T. Miura, K. Kusumoto, M. Gotoh, H. Hayashi and K. Otsubo ; Biochemical and biophysical research communications, 234, 269 (1997)

2 ) K. Hanaoka ; Journal of Applied Electrochemistry, 31, 1307 (2001)

3 ) M. Kato, K. Niikura, S. Hoshino and I. Ohno ; Journal of the Surface Finishing Society of Japan, 42, 729 (1991)

4 ) Mudenkai mekki kiso to oyo (Basics and application of electroless plating), Denki Mekki Kenkyu-kai, Nikkan Kogyo Shinbunsya (Tokyo, 1994) 